\title{
Efficacy of Physical Therapy Interventions on Quality of Life and Upper Quadrant Pain Severity in Women With Post-Mastectomy Pain Syndrome: A Systematic Review and Meta-Analysis
}

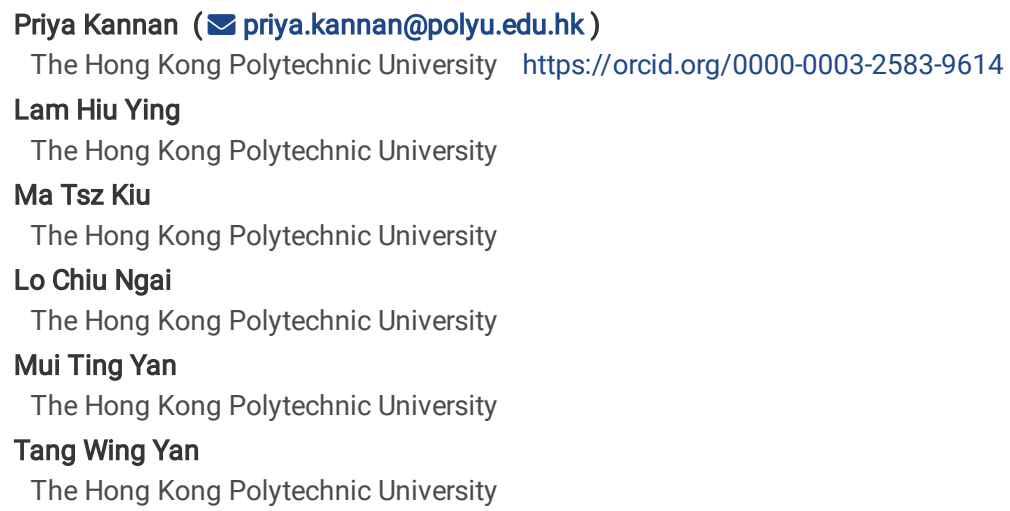

Version of Record: A version of this preprint was published at Quality of Life Research on June 29th, 2021. See the published version at https://doi.org/10.1007/s11136-021-02926-x. 


\section{Abstract}

Purpose: To determine the efficacy of physical therapy interventions on quality of life (QoL) and pain severity in women with post-mastectomy pain syndrome (PMPS).

Methods: Multiple databases were searched from database inception-October 2020. Randomized controlled trials comparing physical therapy interventions to control were included.

Results: Eighteen trials were included in the review. The pooled analysis of the four exercise trials revealed a statistically significant effect of the intervention on general $(p=0.001)$, physical $(p=0.044)$ and mental health components $(p=0.027)$ of $Q$ oL, when compared to the control condition. Pooled analysis of data from six exercise trials revealed a significant effect of exercise interventions compared to control on pain severity $(p<0.001)$. Meta-analysis of data from two myofascial release trials showed a significantly greater reduction in pain severity in the intervention group compared to the control group $(p=0.04)$. The pooled analysis of data from two acupuncture trials revealed a significant reduction in pain severity in the intervention group compared to the control group $(p=0.003)$. Pooled analysis of data from two trials revealed a non-significant effect of compression therapy compared to control on pain severity ( $>0.05)$

Conclusion: This review found that exercise is beneficial for improving QoL and alleviating upper quadrant pain severity in women with PMPS. Myofascial release and acupuncture were more effective than the control condition in reducing the pain severity in PMPS. The effect of compression therapy, complex decongestive therapy and neuromuscular taping on PMPS remains inconclusive, and future research is required to validate the effect of these interventions on PMPS.

\section{Introduction}

Breast cancer is the most commonly diagnosed cancer among women. ${ }^{1}$ Nearly 2.1 million new breast cancer cases were diagnosed in 2018 globally, comprising $11.6 \%$ of total cancer cases. ${ }^{1}$ Breast cancer accounted for $27 \%$ of all new cancer cases in Hong Kong in $2017 .{ }^{2}$ Women diagnosed with early-stage breast cancer frequently undergo surgical procedures, with nearly half undergoing breast-conserving surgery and one third mastectomy. ${ }^{3}$

Post-mastectomy pain syndrome (PMPS) is defined as chronic neuropathic pain affecting the upper quadrant (including the breast, chest wall, axilla, and ipsilateral medial arm) after breast cancer surgery. ${ }^{4}$ PMPS is a frequent complication of breast surgery and affects $28.2-64.1 \%$ of post-mastectomy patients worldwide. ${ }^{4-6}$ PMPS occurs following all kinds of breast surgery, including mastectomy, lumpectomy, and quadrantectomy with axillary lymphadenectomy. ${ }^{5}$ Post-mastectomy pain is associated with damage to nervous tissue, in particular the intercostobrachial, medial pectoral, lateral pectoral, thoracodorsal, or long thoracic nerves. ${ }^{7}$ In PMPS, symptoms are localized to the breast, chest wall, axilla, and ipsilateral arm and persist for at least six months postoperatively. ${ }^{8}$ Post-mastectomy pain interferes with upper limb function and lowers women's quality of life (QoL). ${ }^{9}$

Breast cancer surgery negatively affects women's daily activities, body image, and emotions. ${ }^{10}$ A recent study evaluating upper limb function and QoL in breast cancer survivors who underwent breast cancer surgery reported that post-operative breast cancer patients have average upper limb function and decreased QoL, especially in those who presented with upper limb pain. ${ }^{10}$ Therefore, it is paramount to also evaluate the efficacy of physical therapy interventions to improve QoL in post-operative breast cancer patients with PMPS - a topic that, to the best of our knowledge, has not been evaluated in any systematic reviews to date.

Effective multidisciplinary treatments for PMPS includes pharmacotherapy, physical therapy, and psychological therapy. ${ }^{11}$ Physical therapy interventions that have been proposed for reducing post-mastectomy pain include exercise, acupuncture, cryotherapy, biofeedback, transcutaneous electrical nerve stimulation, and massage therapy. ${ }^{12} \mathrm{~A}$ systematic review investigating the effectiveness of postoperative physical therapy interventions on upper-limb pain in breast cancer patients identified exercise (i.e., manual stretching and active exercises) as effective for treating postoperative breast cancer pain. ${ }^{11}$ However, the review did not include a meta-analysis and was published over five years ago. ${ }^{11}$ Absent quantitative synthesis of data in systematic reviews, there is a potential for possible biases and errors, which may lower the overall quality of the review. ${ }^{13}$ Therefore, there is a need for a systematic review with metaanalysis to evaluate the efficacy of physical therapy interventions for the treatment of PMPS. The objective of this review was to determine the efficacy of physical therapy interventions on both QoL and upper quadrant pain in women with PMPS.

\section{Materials And Methods}

This systematic review was developed and is reported in accordance with the Preferred Reporting Items for Systematic review and Meta-Analyses guidelines. This review is registered in the PROSPERO registry (CRD42020179900).

\section{Search Strategy and Study Screening}

Databases-including AMED, CINAHL, Cochrane Central Register of Controlled Trials (CENTRAL), EMBASE, Medline, PEDro, PubMed, Scopus, and Web of Science were searched from database inception until April 2020. Searches were updated in October 2020. The specific search strategy used for retrieving potentially relevant trials is presented in supplementary Appendix 1 . The reference lists of relevant systematic reviews were also manually searched in order to identify any other potentially eligible trials. Disagreements regarding study selection were resolved by discussion between the two reviewers. A third reviewer (PK) was consulted for any unresolved disagreements. 
Eligibility criteria for the review were defined following the Preferred Reporting Items for Systematic Reviews and Meta-Analyses (PRISMA) guidelines. ${ }^{14}$ The inclusion criteria were: (1) RCTs (parallel, crossover, or pilot) that compared the effect of various physiotherapy interventions to control (no treatment, standard care, sham, placebo, usual care, or active control) on QoL and upper quadrant pain in women with PMPS; (2) trials that utilized either the 36-Item Short Form Survey (SF-36) or 12-Item Short Form Survey (SF-12) for measurement of QoL or the Visual Analog Scale (VAS), Numeric Pain Rating Scale (NPRS), or Brief Pain Inventory (BPI) (short form, Q3-6) for measurement of pain severity; and (3) full-text studies published in either English or Chinese (traditional or simplified). Studies were excluded if they (1) compared two physiotherapy interventions or two different treatment parameters, (2) combined more than one intervention in either treatment group or control group, (3) involved subjects with other cancers (such as ovarian, uterine, etc.) in addition to breast cancer, (4) aimed to prevent secondary lymphedema, (4) measured arm volume/circumference as outcome measures, or (6) were quasi-experimental trials.

\section{Data Extraction}

Data extraction was conducted by two independent reviewers. Relevant data extracted from each study included: last name of the first author, publication year, country, mean age of participants, sample size in each study group, intervention and control, outcome measures, and data (mean and standard deviation [SD]) reported at baseline (pre-intervention) and at the end of the longest follow-up period. If any study reported results as non-parametric data (i.e. median and interquartile-range) unsuitable for meta-analysis, Bland's and Wan's methods were applied to calculate the mean and SD. ${ }^{15,16}$

\section{Quality Assessment}

The methodological quality of the RCTs was evaluated by two independent reviewers using the Physiotherapy Evidence Database (PEDro) scoring system. Trials that scored $\geq 6$ were considered to be of high quality, scores of 4 to 5 were considered fair quality, and scores $<4$ were considered poor quality. ${ }^{17}$

The quality of the evidence in each RCT was assessed using the Grading of Recommendations, Assessment, Development, and Evaluation (GRADE) tool. In the GRADE system, the quality of evidence is categorized as 'high,' 'moderate,' 'low,' or 'very low.'18 GRADE profiler software (version 3.6.1,

http://tech.cochrane.org/revman/other-resources/gradepro/download) developed by the GRADE group was used to rate the quality of evidence. Five factors were considered for rating the quality of evidence: risk of bias, imprecision, inconsistency, indirectness, and publication bias. ${ }^{18}$ Trials were downgraded for risk of bias for the following reasons: lack of allocation concealment, lack of assessor/therapist blinding, loss of $>15 \%$ of participants over follow-up, selective outcome reporting, cessation of the study for a benefit, and failure to perform an intention-to-treat analysis. ${ }^{19}$ Trials were downgraded for precision level if there was minimal or no overlap of confidence intervals (Cls) or if the total number of participants included in the review was smaller than the sample size required for an adequately powered trial. ${ }^{20}$ Optimal Information Size (OIS) was used to determine the necessary sample size required for an adequately powered trial. To inform this decision, the OIS for a two-arm parallel-group trial was calculated using data from a previous study, assuming an a of 0.05 and $80 \%$ power $(\beta=0.2) .{ }^{21}$ Trials were downgraded for inconsistency if there was evidence of clinical or statistical heterogeneity as indicated by a large $\mathrm{I}^{2}$ value (> $50 \%){ }^{22}$ Trials were downgraded for indirectness if there was a difference between the populations, interventions, or outcome measures (surrogate outcomes) across trials. ${ }^{23}$ Trials were downgraded for publication bias if they were commercially funded, likely to be sponsored by industry, or if the authors shared a conflict of interest. ${ }^{24}$

\section{Data Synthesis and Analysis}

Meta-analyses were conducted using Comprehensive Meta-Analysis (CMA) software, version 3. Trials of similar interventions and outcome measures were pooled together. For QoL, the differences in mean and 95\% Cl were calculated. For pain measurement, Hedges' g (standardized mean difference [SMD]) and $95 \%$ Cls were computed because of different measurement scales across trials. Statistical heterogeneity was assessed using the Chi-square test $\left(\mathrm{I}^{2}\right)$. A $p$ value $\leq 0.05$ was defined as statistical significance.

\section{Results}

Figure 1 summarizes the study selection process based on the PRISMA approach. Trials excluded at the full-text screening stage and the reasons for exclusion are listed in supplementary Appendix 2. Electronic and manual searching identified 17,759 articles. Eighteen trials met the inclusion criteria and were included in the review. All 18 trials provided data for pooling and were included in the meta-analysis.

\section{Characteristics of Included Trials}

The characteristics of the included trials are summarized in Table 1. Among the 18 included trials, 17 trials ${ }^{21,25-40}$ were parallel-group RCTs and one trial ${ }^{30}$ was a cross-over design. Nine trials were conducted in Europe, ${ }^{27,29-33,36,38,41}$ three in Asia, ${ }^{21,34,37}$ five in North America, ${ }^{25,26,28,35,39}$ and one in South America. ${ }^{40}$

\section{Participants}

Data from 1,098 women were collected across the 18 trials included in the meta-analysis. The sample size of included trials ranged from 23 to 291 . Mean participant age ranged from 45.6 to 67.8 years.

\section{Interventions}

Nine trials ${ }^{21}, 27-29,32,34,35,39,40$ compared the effectiveness of exercise to a control group. One trial ${ }^{37}$ compared shoulder exercise with a historical control group that received usual care. Two trials ${ }^{30,41}$ compared myofascial release to a placebo group. Two trials ${ }^{25,26}$ compared acupuncture to a usual care control

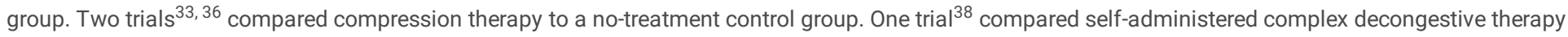
(CDT) to a usual care control group. One trial ${ }^{31}$ compared neuromuscular taping (NMT) to sham-NMT. 


\section{Outcome measures}

Of the 18 included trials, four reported QoL and 14 reported pain severity. For QoL, three trials utilized SF-36 $21,35,40$ and one utilized SF-12. ${ }^{32}$ Of the 14 trials that measured pain severity, eight trials utilized VAS, ${ }^{29-31,33,34,36,39,41}$ four utilized NPRS, ${ }^{26-28,38}$ one utilized BPI-SF, ${ }^{25}$ and one utilized both VAS and BPI. ${ }^{37}$

\section{Methodological Quality}

The PEDro quality of the included trials is presented in Table 2. The mean PEDro score of the 18 trials was 6.2 out of 10. Twelve trials ${ }^{21,27-29,31,32,35-39,41}$ were considered to be of high methodological quality, scoring $\geq 6$ out of 10 . Five trials $25,26,30,34,40$ were of fair quality, scoring 5 on the PEDro scale, and one trial $^{33}$ was poor quality scoring, 3 out of 10 . Of the 18 included trials, 17 lacked therapist blinding, nine did not report allocation concealment, nine lacked intention-to-treat analysis, eight lacked assessor blinding, and six trials lost $>15 \%$ of participants to follow-up.

\section{Quality of Evidence (GRADE)}

The GRADE evidence profiles for individual interventions on each outcome measure are shown in Table 3. The overall quality of evidence for trials of myofascial release, neuromuscular taping, and self-administered complex decongestive therapy was 'moderate,' while the quality of evidence was 'low' for trials of compression therapy and 'very low' for trials of acupuncture and exercise. Serious risk of bias was the main factor contributing to downgraded quality of evidence, and this was identified by both the GRADE assessment and the PEDro scale.

Given the serious risk of bias as revealed by the GRADE assessment and the PEDro scale, the overall GRADE quality of evidence for the included trials ranged from very low to moderate. Inconsistency, which was not assessed in the PEDro scale, could be another factor underlying the decline in GRADE quality. Very serious inconsistency was recognized in all exercise trials. One trial was downgraded for publication bias because a conflict of interest was not reported. ${ }^{26}$ Since the number of participants included in this systematic review is more than the sample size necessary for an adequately powered trial, this OIS criterion was met and therefore trials were not downgraded for imprecision. Furthermore, none of the included trials were downgraded for indirectness.

\section{Effects of Intervention on QoL}

\section{Exercise vs. control}

Data were pooled from four trials $21,32,35,40$ of fair-to-high methodological quality and very low-grade evidence comparing the effect of exercise to a control condition on general, physical, and mental health components of QoL. Of the four trials, three ${ }^{21,35,40}$ measured QoL using the SF-36 and one ${ }^{32}$ measured QoL using the SF-12. The pooled analysis of the four trials ( $n=451$ women with PMPS) revealed a statistically significant effect of the intervention on general (SMD 0.865 [95\% Cl: 0.360 to 1.371]; $p=0.001$; Fig. 2a), physical (SMD 0.335 [95\% Cl: 0.009 to 0.661]; $p=0.044$; Fig. 2b) and mental health components (SMD 0.270 [95\% Cl: 0.030 to 0.510$]$; $=0.027$; Fig. $2 \mathrm{c}$ ), when compared to the control condition.

\section{Effects of Interventions on Pain Severity}

\section{Exercise vs. control}

Data were pooled from six 27-29, 34,37,39 trials of fair-to-high methodological quality and very low-grade evidence comparing the effect of exercise (aerobic, resistive, water exercise, nerve gliding, and stretching) to a control group. Of these six trials, one trial ${ }^{37}$ included three groups (scapula-oriented shoulder exercise, general exercise, and a control group), and data from the two exercise intervention groups versus the same control group were included individually. Of the six trials included in the meta-analysis, one trial ${ }^{37}$ measured pain severity with both VAS and BPI, two trials ${ }^{27,28}$ used NPRS, and three trials ${ }^{29,34,39}$ utilized only VAS. Pooled analysis of the six trials $(n=406$ women with PMPS) revealed a significantly greater reduction in pain severity in the intervention group than the control group (SMD - 1.000 [95\% Cl: -1.481 to -0.519$]$; $p<0.001$; Fig. 3a).

\section{Myofascial release vs. placebo}

Data were pooled from two trials ${ }^{30,41}$ of fair-to-high methodological quality and moderate-grade evidence comparing the effect of myofascial release to placebo. Pooled analysis of the data from these two trials $(n=45$ women with PMPS) showed a statistically significant effect of the intervention compared to placebo (SMD - 0.649 [95\% Cl: -1.293 to -0.005$] ; p=0.04$; Fig. 3b).

\section{Acupuncture vs. control}

Data were pooled from two trials ${ }^{25,26}$ of fair methodological quality and very low-grade evidence comparing the effect of acupuncture to usual care. One trial $^{26}$ measured pain intensity with NPRS and one trial ${ }^{25}$ used BPI-SF. Pooled analysis $(n=55)$ revealed a statistically significant reduction in pain severity in the acupuncture group (SMD - 0.817 [95\% Cl: -1.357 to -0.278$]$; $p=0.003$; Fig. 3c) than in the control group.

\section{Self-administered CDT vs. usual care}

One small trial ${ }^{38}(n=41)$ of high methodological quality and moderate-grade evidence compared the effect of CDT to usual care. The trial showed a statistically significant effect of CDT compared to usual care control (standard mean difference [SMD] -0.749 [95\% Cl: -1.382 to -0.115$]$; $p=0.020$; Fig. 3d).

\section{Neuromuscular taping vs. sham-NMT}


One small trial ${ }^{31}(n=40)$ of high methodological quality and moderate-grade evidence compared the effect of neuromuscular taping to sham-NMT on pain severity. The trial showed a statistically significant effect of NMT compared to sham (SMD -2.812 [95\%Cl: -3.686 to -1.938 ]; $p<0.001$; Fig. 3e).

\section{Compression therapy vs. control}

Data were pooled from two ${ }^{33,36}$ trials with low-grade evidence and a range of poor-to-high methodological quality comparing the effect of compression therapy to control (i.e. no physiotherapy treatment). Pooled analysis $(n=60)$ revealed a non-significant effect of the intervention compared to control (SMD 0.292 [95\% Cl: -0.260 to 0.845$] ; p=0.299 ;$ Fig. 3f).

\section{Discussion}

This review evaluated the efficacy of physiotherapy interventions compared to control for the management of upper quadrant pain in PMPS. 17,759 potentially relevant articles were identified, and of these 18 met the inclusion criteria and were included in the review.

The pooled analysis of data from four trials $21,32,35,40$ showed a significant effect of exercise compared to control on general, physical, and mental health components of QoL in women with PMPS. The exercise parameters in the four trials ranged from 30 to 60 minute sessions, performed two to five times per week for a duration of three months to two years. The types of exercises included aerobic exercise, resistance training, ${ }^{21,32,35,40}$ and aqua fitness exercise. ${ }^{32}$ Aerobic exercise ${ }^{40}$ was performed on the treadmill at an intensity of $60-80 \%$ HR maximum. Resistance training ${ }^{32}$ included exercises for the large muscles of the upper and lower limbs progressing from two sets of 12 repetitions at 50-60\% 1RM to three sets of 10 repetitions at $60-80 \% 1$ RM, over a period of two years. Aqua fitness exercise ${ }^{32}$ consisted of aerobic and resistance exercise for the chest, shoulder, lower limbs, and core muscles.

The results obtained in this review for QoL concur with the results of a previous systematic review by Cheema et al (2007), ${ }^{42}$ evaluating the efficacy of progressive resistance training in combination with aerobic training. Similar to the current review, this review also identified progressive resistance training in combination with low-to-moderate intensity aerobic training at $60-80 \% \mathrm{HR}$ maximum as efficacious for improving the QoL in women with PMPS. Exercise is a safe intervention; none of the included exercise trials reported any occurrence of adverse events. Given the evidence from the current review for the beneficial effects of exercise, as well as the findings of previous reviews, exercise (such as resistance exercise, aerobic training, and hydrotherapy) is recommended for reducing pain severity and improving QoL in women with PMPS.

Pooled analysis of data from six exercise trials ${ }^{27-29,34,37,39}$ showed a statistically significant effect of exercise interventions over control for pain severity in women with PMPS. The exercise parameters in the six trials ranged in session length from 50 to 90 minutes (including 10 minutes warm-up and 10 minutes cool-down), in frequency from one to three times per week, and in duration from five weeks to one year. The types of exercise included in the six trials were aerobic exercise, resistance training ${ }^{27,34,37}$ for the upper limbs (i.e., biceps, triceps, shoulder abductors and extensors, scapular muscles), lower limbs, and trunk muscles, hydrotherapy, ${ }^{29}$ stretching exercises, and nerve gliding exercise. ${ }^{28}$

The current review's findings on the efficacy of exercise interventions for PMPS concur with the systematic review of exercise therapy for shoulder pain related to breast cancer by Tatham et al. (2013), ${ }^{43}$ which reported significant effects of exercise compared to control on shoulder pain in post-mastectomy women. This review evaluated the efficacy of aerobic exercise and strength training on post-mastectomy pain severity, but the current review additionally provides evidence for the efficacy of other therapies such as nerve gliding and water exercise. Another contribution of the current review is that it provides new evidence on reducing upper quadrant pain in PMPS (the previous review by Tatham's et al. (2013) ${ }^{43}$ evaluated shoulder pain only).

Meta-analysis of data from two myofascial release trials ${ }^{30,41}$ showed a significantly greater reduction in pain severity in the intervention group receiving myofascial release compared to the control group. Myofascial release was applied using the Pilat approach ${ }^{44}$ to the upper thoracic and upper limb region, for 30 to 40 minutes per session. Results obtained for this intervention in the current review concurs with the review by Basilio et al. (2014), ${ }^{45}$ which concluded that myofascial therapy applied to the neck, shoulder and chest region is beneficial in reducing upper quadrant pain in post-mastectomy patients. These findings indicate that upper quadrant pain in women with PMPS may be alleviated with myofascial release. However, the long-term effects of myofascial release remain uncertain because the myofascial trials included in both the current review and Basilo et al.'s $(2014)^{45}$ review evaluated short term effects only. Further research is required to evaluate the long-term effects of myofascial release for the treatment of PMPS.

The pooled analysis of data from two acupuncture trials ${ }^{25,26}$ of fair methodological quality and very low-grade quality of evidence revealed a significant reduction in pain severity in patients receiving acupuncture therapy vs. control interventions. One of the two trials provided electroacupuncture in 30 -minute sessions at an alternating frequency of $2-10 \mathrm{~Hz}$, and participants received a total of 18 acupuncture treatments over the course of eight weeks. ${ }^{25} \mathrm{However}$, the other ${ }^{26}$ trial provided inadequate intervention-related information such as the acupoints used, the number of needles inserted, the depth of insertion, and whether needle stimulation was elicited. Based on the results of the current review, acupuncture may be considered for the treatment of upper quadrant pain in PMPS. However, it is difficult to ascertain the role of different acupoints and the depth of insertion for the treatment of upper quadrant pain in women with PMPS because the included trials did not provide adequate intervention-related information. Future acupuncture trials must follow the STRICTA checklist while reporting intervention-related information.

Pooled analysis of data from two trials ${ }^{33,36}$ of poor-to-high methodological quality and low quality of evidence showed a non-significant effect of compression therapy compared to control on pain severity. One ${ }^{33}$ trial provided a compression corset while the other ${ }^{36}$ provided participants with a compression-type sports bra. Given the limited evidence and quality of the two trials, the efficacy of compression therapy for the treatment of PMPS remains inconclusive. Future adequately powered trials are warranted to investigate the effectiveness of CDT for the treatment of upper quadrant pain in PMPS. 
Analysis of data from one small trial ${ }^{38}(n=41)$ evaluating the effect of CDT on pain severity using NRPS in women with PMPS revealed a significant effect of the intervention compared to control. This was achieved with ten sessions of CDT (each lasting for 1.5 hours) over the course of four weeks. The content of the CDT course included manual lymphatic self-drainage, self-bandage, breathing exercises, mobilization exercises, muscle reinforcement exercises, muscle contracture management, and education around the physiology underlying development of post-mastectomy lymphedema. ${ }^{38}$ It is worth noting that the reduction in pain score (2.2) is well above the clinically worthwhile threshold of 2 for NPRS. ${ }^{46}$ However, this result was derived from a single small trial ${ }^{38}$ involving only 41 participants, so further data from larger studies are required to confirm the efficacy of CDT for PMPS.

Analysis of data from a single small $(n=40)$ study of high methodological quality and moderate-grade evidence ${ }^{31}$ revealed a significant effect of NMT compared to control on pain severity, measured with the VAS. To achieve this result, NMT was applied to the cervical, wrist-forearm, and lumbosacral regions for three seven-day sessions over the course of five weeks. It is worth noting that the mean reduction in pain (2.8) was greater than the clinically worthwhile threshold of 2 , and the $95 \% \mathrm{Cl}$ (3.6 to 1.9) extends well above and below this threshold. ${ }^{46}$ Replication of this result in other adequately powered trials should be sought before any definitive conclusions can be made for the NMT intervention.

This systematic review has several strengths. This review identified significant benefits for several physiotherapy interventions-including exercise therapy, myofascial release and acupuncture-in improving the QoL and reducing pain severity in women with PMPS. A comprehensive search strategy was utilized to identify trials evaluating the effectiveness of physiotherapy interventions for the treatment of upper quadrant pain in women with PMPS. More than half of the studies (12 of 18) included in the review were of high methodological quality. Furthermore, more than half (10 of 18) of the studies reported assessor blinding, thereby minimizing bias. Publication bias is important to both meta-analysis and the interpretation of trials showing a statistically significant positive result. ${ }^{47}$ However, we could not evaluate the impact publication bias in our review due to the small number of studies included in each meta-analysis (at least 8-10 studies are required for running a funnel plot to assess publication bias).

\section{Conclusions}

Meta-analysis revealed significant effects of exercise compared to control in improving both pain and QoL. This review suggests that exercise, acupuncture, and myofascial release can improve pain severity in women with PMPS. Exercise is a low-cost and safe intervention and should therefore be considered for clinical use. Our meta-analysis also showed positive treatment effects for acupuncture for PMPS, but future acupuncture trials must provide a detailed description of the intervention as outlined in the STRICTA checklist to establish which acupoints and what particular needling regimen is optimal or the treatment of PMPS. The pooled analysis of myofascial release trials identified significant effects for this intervention compared to control on pain severity, and these results are consistent with the results reported in the literature. Myofascial release can therefore be considered for treating PMPS, although further studies are warranted. Our analysis also suggests that CDT and NMT compared can significantly reduce the pain severity in women PMPS compared to control. However, considering that these are from single studies of CDT and NMT, future well-designed RCTs are required to provide more precise estimates of the average effects of CDT and NMT for PMPS. Future studies are needed to determine the effectiveness of physiotherapy interventions besides exercise for improving QoL in women with PMPS and to determine the optimal parameters (i.e., frequency, intensity, and duration) for exercise interventions for PMPS.

\section{Declarations}

Ethics approval: Not applicable

Consent to participate. Not applicable

Funding. No funding was obtained for this study.

\section{Conflicts of interest}

We have no conflicts of interest to disclose.

\section{References}

1. Bray F, Ferlay J, Soerjomataram I, Siegel RL, Torre LA, Jemal A. Global cancer statistics 2018: GLOBOCAN estimates of incidence and mortality worldwide for 36 cancers in 185 countries. CA Cancer J Clin. 2018;68(6):394-424.

2. Hong Kong Cancer Registry HA. Female breast cancer in 2017 Hong Kong [updated Oct 2019; cited Hong Kong Cancer Registry, Hospital Authority. Available from: https://www3.ha.org.hk/cancereg/pdf/factsheet/2017/breast_2017.pdf

3. DeSantis CE, Ma J, Gaudet MM, Newman LA, Miller KD, Goding Sauer A, et al. Breast cancer statistics, 2019. CA Cancer J Clin. 2019;69(6):438-51.

4. Beyaz SG, Ergönenç J, Ergönenç T, Sönmez Ö U, Erkorkmaz Ü, Altintoprak F. Postmastectomy Pain: A Cross-sectional Study of Prevalence, Pain Characteristics, and Effects on Quality of Life. Chin Med J (Engl). 2016;129(1):66-71.

5. Couceiro TC, Valença MM, Raposo MC, Orange FA, Amorim MM. Prevalence of post-mastectomy pain syndrome and associated risk factors: a crosssectional cohort study. Pain Manag Nurs. 2014;15(4):731-7.

6. Gong Y, Tan Q, Qin Q, Wei C. Prevalence of postmastectomy pain syndrome and associated risk factors: A large single-institution cohort study. Medicine (Baltimore). 2020;99(20):e19834.

7. Couceiro TC, Menezes TC, Valênça MM. Post-mastectomy pain syndrome: the magnitude of the problem. Rev Bras Anestesiol. 2009;59(3):358-65. 
8. Waltho D, Rockwell G. Post-breast surgery pain syndrome: establishing a consensus for the definition of post-mastectomy pain syndrome to provide a standardized clinical and research approach - a review of the literature and discussion. Can J Surg. 2016;59(5):342-50.

9. Rietman JS, Dijkstra PU, Hoekstra HJ, Eisma WH, Szabo BG, Groothoff JW, et al. Late morbidity after treatment of breast cancer in relation to daily activities and quality of life: a systematic review. Eur J Surg Oncol. 2003;29(3):229-38.

10. Recchia TL, Prim AC, Luz CMd. Upper Limb Functionality and Quality of Life in Women with Five-Year Survival after Breast Cancer Surgery. Rev Bras Ginecol Obstet. 2017;39(3):115-22.

11. De Groef A, Van Kampen M, Dieltjens E, Christiaens MR, Neven P, Geraerts I, et al. Effectiveness of postoperative physical therapy for upper-limb impairments after breast cancer treatment: a systematic review. Arch Phys Med Rehabil. 2015;96(6):1140-53.

12. Silver J, Mayer RS. Barriers to pain management in the rehabilitation of the surgical oncology patient. J Surg Oncol. 2007;95(5):427-35.

13. Lee YH. Strengths and Limitations of Meta-Analysis. The Korean journal of medicine. 2019;94(5):391-5.

14. Liberati A, Altman DG, Tetzlaff J, Mulrow C, Gøtzsche PC, loannidis JPA, et al. The PRISMA Statement for Reporting Systematic Reviews and MetaAnalyses of Studies That Evaluate Health Care Interventions: Explanation and Elaboration. PLoS Med. 2009;6(7):e1000100-e.

15. Bland M. Estimating mean and standard deviation from the sample size, three quartiles, minimum, and maximum. International Journal of Statistics in Medical Research. 2014;4(1):57-64.

16. Wan X, Wang W, Liu J, Tong T. Estimating the sample mean and standard deviation from the sample size, median, range and/or interquartile range. BMC Med Res Methodol. 2014;14(1):135-.

17. Cashin AG, McAuley JH. Clinimetrics: Physiotherapy Evidence Database (PEDro) Scale. J Physiother. 2019;66(1):59-.

18. Balshem H, Helfand M, Schünemann HJ, Oxman AD, Kunz R, Brozek J, et al. GRADE guidelines: 3. Rating the quality of evidence. J Clin Epidemiol. 2011;64(4):401-6.

19. Guyatt GH, Oxman AD, Vist G, Kunz R, Brozek J, Alonso-Coello P, et al. GRADE guidelines: 4. Rating the quality of evidence-study limitations (risk of bias). J Clin Epidemiol. 2011;64(4):407-15.

20. Guyatt GH, Oxman AD, Kunz R, Brozek J, Alonso-Coello P, Rind D, et al. GRADE guidelines 6. Rating the quality of evidence-imprecision. J Clin Epidemiol. 2011;64(12):1283-93.

21. Dong X, Yi X, Gao D, Gao Z, Huang S, Chao M, et al. The effects of the combined exercise intervention based on internet and social media software (CEIBISMS) on quality of life, muscle strength and cardiorespiratory capacity in Chinese postoperative breast cancer patients:a randomized controlled trial. HEALTH QUAL LIFE OUT. 2019;17(1):109-.

22. Guyatt GH, Oxman AD, Kunz R, Woodcock J, Brozek J, Helfand M, et al. GRADE guidelines: 7. Rating the quality of evidence-inconsistency. J CLIN EPIDEMIOL. 2011;64(12):1294-302.

23. Guyatt GH, Oxman AD, Kunz R, Woodcock J, Brozek J, Helfand M, et al. GRADE guidelines: 8. Rating the quality of evidence-indirectness. J CLIN EPIDEMIOL. 2011;64(12):1303-10.

24. Guyatt GH, Oxman AD, Montori V, Vist G, Kunz R, Brozek J, et al. GRADE guidelines: 5. Rating the quality of evidence-publication bias. J CLIN EPIDEMIOL. 2011;64(12):1277-82.

25. Lu W, Giobbie-Hurder A, Freedman RA, Shin IH, Lin NU, Partridge AH, et al. Acupuncture for Chemotherapy-Induced Peripheral Neuropathy in Breast Cancer Survivors: A Randomized Controlled Pilot Trial. Oncologist. 2019;25(4):310-8.

26. Quinlan-Woodward J, Gode A, Dusek J, Reinstein A, Johnson J, Sendelbach S. Assessing the Impact of Acupuncture on Pain, Nausea, Anxiety, and Coping in Women Undergoing a Mastectomy. ONCOL NURS FORUM. 2016;43(6):725-32.

27. Ammitzbøll G, Andersen KG, Bidstrup PE, Johansen C, Lanng C, Kroman N, et al. Effect of progressive resistance training on persistent pain after axillary dissection in breast cancer: a randomized controlled trial. BREAST CANCER RES TR. 2019;179(1):173-83.

28. Andersen Hammond E, Pitz M, Steinfeld K, Lambert P, Shay B. An Exploratory Randomized Trial of Physical Therapy for the Treatment of ChemotherapyInduced Peripheral Neuropathy. NEUROREHAB NEURAL RE. 2020;34(3):154596831989991-246.

29. Cantarero-Villanueva I, Fernández-Lao C, Fernández-de-las-Peñas C, López-Barajas IB, Del-Moral-Ávila R, de la-Llave-Rincón Al, et al. Effectiveness of Water Physical Therapy on Pain, Pressure Pain Sensitivity, and Myofascial Trigger Points in Breast Cancer Survivors: A Randomized, Controlled Clinical Trial. PAIN MED. 2012;13(11):1509-19.

30. Castro-Martín E, Ortiz-Comino L, Gallart-Aragón T, Esteban-Moreno B, Arroyo-Morales M, Galiano-Castillo N. Myofascial Induction Effects on NeckShoulder Pain in Breast Cancer Survivors: Randomized, Single-Blind, Placebo-Controlled Crossover Design. Archives of Physical Medicine \& Rehabilitation. 2017;98(5):832-40.

31. Conejo I, Pajares B, Alba E, Cuesta-Vargas Al. Effect of neuromuscular taping on musculoskeletal disorders secondary to the use of aromatase inhibitors in breast cancer survivors: A pragmatic randomised clinical trial. BMC Complementary and Alternative Medicine. 2018;18(1).

32. García-Soidán JL, Pérez-Ribao I, Leirós-Rodríguez R, Soto-Rodríguez A. Long-Term Influence of the Practice of Physical Activity on the Self-Perceived Quality of Life of Women with Breast Cancer: A Randomized Controlled Trial. Int J Environ Res Public Health. 2020;17(14).

33. Hansdorfer-Korzon R, Teodorczyk J, Gruszecka A, Wydra J, Lass P. Relevance of low-pressure compression corsets in physiotherapeutic treatment of patients after mastectomy and lymphadenectomy. Patient preference and adherence. 2016;10:1177-87.

34. Hwang JH, Chang HJ, Shim YH, Park WH, Park W, Huh SJ, et al. Effects of supervised exercise therapy in patients receiving radiotherapy for breast cancer. Yonsei medical journal. 2008;49(3):443-50.

35. Irwin ML, Cadmus L, Alvarez-Reeves M, O’Neil M, Mierzejewski E, Latka R, et al. Recruiting and Retaining Breast Cancer Survivors into a Randomized Controlled Exercise Trial: The Yale Exercise and Survivorship Study. Cancer. 2008;112(11 Suppl):2593-606.

Page $7 / 14$ 
36. Johansson K, Jönsson C, Björk-Eriksson T. Compression Treatment of Breast Edema: A Randomized Controlled Pilot Study. Lymphat Res Biol. 2020;18(2):129-35.

37. Lee SA, Kang J, Kim YD, An AR, Kim S, Kim Y, et al. Effects of a scapula-oriented shoulder exercise programme on upper limb dysfunction in breast cancer survivors: a randomized controlled pilot trial. Clinical Rehabilitation. 2010;24(7):600-13.

38. Ligabue MB, Campanini I, Veroni P, Cepelli A, Lusuardi M, Merlo A. Efficacy of self-administered complex decongestive therapy on breast cancer-related lymphedema: a single-blind randomized controlled trial. Breast Cancer Research and Treatment. 2019;175(1):191-201.

39. Nyrop KA, Callahan LF, Cleveland RJ, Arbeeva LL, Hackney BS, Muss HB. Randomized Controlled Trial of a Home-Based Walking Program to Reduce Moderate to Severe Aromatase Inhibitor-Associated Arthralgia in Breast Cancer Survivors. Oncologist. 2017;22(10):1238-49.

40. Paulo TRS, Rossi FE, Viezel J, Tosello GT, Seidinger SC, Simões RR, et al. The impact of an exercise program on quality of life in older breast cancer survivors undergoing aromatase inhibitor therapy: a randomized controlled trial. Health Qual Life Outcomes. 2019;17(1):17-.

41. Serra-Añó P, Inglés M, Bou-Catalá C, Iraola-Lliso A, Espí-López GV. Effectiveness of myofascial release after breast cancer surgery in women undergoing conservative surgery and radiotherapy: a randomized controlled trial. Supportive care in cancer : official journal of the Multinational Association of Supportive Care in Cancer. 2019;27(7):2633-41.

42. Cheema B, Gaul CA, Lane K, Fiatarone Singh MA. Progressive resistance training in breast cancer: a systematic review of clinical trials. Breast cancer research and treatment. 2008;109(1):9-26.

43. Tatham B, Smith J, Cheifetz O, Gillespie J, Snowden K, Temesy J, et al. The Efficacy of Exercise Therapy in Reducing Shoulder Pain Related to Breast Cancer: A Systematic Review. Physiotherapy Canada. 2013;65(4):321-30.

44. Pilat A. 7.4 - Myofascial induction approaches. In: Schleip R, Findley TW, Chaitow L, Huijing PA, editors. Fascia: The Tensional Network of the Human Body. Oxford: Churchill Livingstone; 2012. p. 311-7.

45. Basilio FB, de Medeiros Miranda dos Anjos R, de Medeiros EP, de Melo EMF, da Silva RMV. Effects of manual therapy techniques in the treatment of pain in post mastectomy patients: systematic review. Manual Therapy, Posturology \& Rehabilitation Journal. 2014;12(1):196-201.

46. Farrar JT, Young JP, LaMoreaux L, Werth JL, Poole RM. Clinical importance of changes in chronic pain intensity measured on an 11-point numerical pain rating scale. PAIN. 2001;94(2):149-58.

47. Dickersin K, Chan S, Chalmersx TC, Sacks HS, Smith H. Publication bias and clinical trials. Controlled Clinical Trials. 1987;8(4):343-53.

\section{Tables}

Table 1 is not available with this version.

Table 2. PEDro scores of included trials $(n=18)$. 


\begin{tabular}{|c|c|c|c|c|c|c|c|c|c|c|c|}
\hline Trial & $\begin{array}{l}\text { Random } \\
\text { allocation }\end{array}$ & $\begin{array}{l}\text { Concealed } \\
\text { allocation }\end{array}$ & $\begin{array}{l}\text { Baseline } \\
\text { comparability }\end{array}$ & $\begin{array}{l}\text { Participant } \\
\text { blinding }\end{array}$ & $\begin{array}{l}\text { Therapist } \\
\text { blinding }\end{array}$ & $\begin{array}{l}\text { Assessor } \\
\text { blinding }\end{array}$ & $\begin{array}{l}\text { Adequate } \\
\text { follow-up }\end{array}$ & $\begin{array}{l}\text { Intention- } \\
\text { to-treat } \\
\text { analysis }\end{array}$ & $\begin{array}{l}\text { Between- } \\
\text { group } \\
\text { comparisons }\end{array}$ & $\begin{array}{l}\text { Point } \\
\text { estimate } \\
\text { and } \\
\text { variability }\end{array}$ & \\
\hline $\begin{array}{l}\text { Ammitzbol } \\
2019^{28}\end{array}$ & Y & Y & Y & N & $\mathrm{N}$ & Y & Y & Y & Y & Y & 8 \\
\hline $\begin{array}{l}\text { Andersen- } \\
\text { Hammond } \\
2020^{29}\end{array}$ & Y & Y & Y & N & N & Y & N & $\mathrm{N}$ & Y & Y & 6 \\
\hline $\begin{array}{l}\text { Cantarero- } \\
\text { Villanueva } \\
2012^{30}\end{array}$ & Y & Y & Y & $\mathrm{N}$ & $\mathrm{N}$ & Y & Y & Y & Y & Y & 8 \\
\hline $\begin{array}{l}\text { Castro- } \\
\text { Martín } \\
2017^{31}\end{array}$ & $Y$ & $\mathrm{~N}$ & $Y$ & $\mathrm{~N}$ & $\mathrm{~N}$ & $\mathrm{~N}$ & $Y$ & $\mathrm{~N}$ & $Y$ & $\mathrm{Y}$ & 5 \\
\hline $\begin{array}{l}\text { Conejo } \\
2018^{32}\end{array}$ & Y & $Y$ & $Y$ & $\mathrm{~N}$ & $\mathrm{~N}$ & $\mathrm{~N}$ & $Y$ & $Y$ & Y & $Y$ & 7 \\
\hline $\begin{array}{l}\text { Dong } \\
2019^{21}\end{array}$ & Y & $Y$ & Y & $\mathrm{N}$ & $\mathrm{N}$ & $Y$ & $\mathrm{~N}$ & $\mathrm{~N}$ & $Y$ & $Y$ & 6 \\
\hline $\begin{array}{l}\text { García- } \\
\text { Soidán } \\
2020^{33}\end{array}$ & Y & Y & Y & $\mathrm{N}$ & N & Y & Y & $\mathrm{N}$ & Y & Y & 7 \\
\hline $\begin{array}{l}\text { Hansdorfer- } \\
\text { Korzon } \\
2016^{34}\end{array}$ & $Y$ & $\mathrm{~N}$ & $\mathrm{~N}$ & $\mathrm{~N}$ & $\mathrm{~N}$ & $\mathrm{~N}$ & $N$ & $N$ & $Y$ & $Y$ & 3 \\
\hline $\begin{array}{l}\text { Hwang } \\
2008^{35}\end{array}$ & Y & N & Y & $\mathrm{N}$ & N & $\mathrm{N}$ & Y & $\mathrm{N}$ & Y & Y & 5 \\
\hline $\begin{array}{l}\text { Irwin } \\
2008^{36}\end{array}$ & Y & Y & Y & N & N & Y & Y & Y & Y & $Y$ & 8 \\
\hline $\begin{array}{l}\text { Johansson } \\
2020^{37}\end{array}$ & Y & N & Y & N & N & Y & Y & $\mathrm{N}$ & $Y$ & Y & 6 \\
\hline Lee $2010^{38}$ & Y & N & Y & $N$ & Y & Y & $\mathrm{N}$ & $N$ & $Y$ & $Y$ & 6 \\
\hline $\begin{array}{l}\text { Ligabue } \\
2019^{39}\end{array}$ & Y & Y & Y & N & N & Y & Y & $Y$ & $Y$ & Y & 8 \\
\hline Lu $2020^{26}$ & Y & N & Y & $N$ & $\mathrm{~N}$ & $N$ & $N$ & $Y$ & $Y$ & $Y$ & 5 \\
\hline $\begin{array}{l}\text { Nyrop } \\
2017^{40}\end{array}$ & Y & N & Y & N & N & N & Y & Y & Y & $Y$ & 6 \\
\hline $\begin{array}{l}\text { Paulo } \\
2019^{41}\end{array}$ & Y & N & Y & N & N & N & N & Y & Y & $Y$ & 5 \\
\hline $\begin{array}{l}\text { Quinlan- } \\
\text { Woodward } \\
2016^{25}\end{array}$ & $Y$ & $\mathrm{~N}$ & $Y$ & $\mathrm{~N}$ & $\mathrm{~N}$ & $\mathrm{~N}$ & $Y$ & $\mathrm{~N}$ & $Y$ & $Y$ & 5 \\
\hline $\begin{array}{l}\text { Serra-Añó } \\
2018^{42}\end{array}$ & $Y$ & Y & $Y$ & $\mathrm{~N}$ & $\mathrm{~N}$ & $Y$ & $Y$ & $Y$ & $Y$ & $Y$ & 8 \\
\hline
\end{tabular}

Y: Yes; N: No

Table 3. GRADE evidence profile (EP) and summary of findings (SoF). 


\begin{tabular}{|c|c|c|c|c|c|c|c|c|c|c|}
\hline \multicolumn{7}{|c|}{ Quality assessment } & \multicolumn{2}{|l|}{ No of patients } & \multicolumn{2}{|l|}{ Effect } \\
\hline No of studies & Design & $\begin{array}{l}\text { Risk of } \\
\text { bias }\end{array}$ & Inconsistency & Indirectness & Imprecision & $\begin{array}{l}\text { Publication } \\
\text { Bias }\end{array}$ & Intervention & Control & $\begin{array}{l}\text { Relative } \\
\text { (95\% } \\
\text { Cl) }\end{array}$ & Absolute \\
\hline \multicolumn{11}{|c|}{ Myofascial release vs. placebo - Outcome: pain (measured with: VAS; better indicated by lower values) } \\
\hline $2^{31,42}$ & $\begin{array}{l}\text { randomised } \\
\text { trials }\end{array}$ & serious ${ }^{\mathrm{a}}$ & $\begin{array}{l}\text { no serious } \\
\text { inconsistency }\end{array}$ & $\begin{array}{l}\text { no serious } \\
\text { indirectness }\end{array}$ & $\begin{array}{l}\text { no serious } \\
\text { imprecision }\end{array}$ & undetected & 32 & 34 & - & $\begin{array}{l}\text { SMD's g } \\
0.649 \\
\text { lower } \\
\text { ( } 1.293 \\
\text { to } 0.005 \\
\text { lower) }\end{array}$ \\
\hline \multicolumn{11}{|c|}{ Exercise vs. control - Outcome: pain (measured with: VAS, BPI, NPRS; better indicated by lower values) } \\
\hline $6^{28,29,30,35,38,40}$ & $\begin{array}{l}\text { randomised } \\
\text { trials }\end{array}$ & $\begin{array}{l}\text { very } \\
\text { serious }^{b}\end{array}$ & very serious ${ }^{c}$ & $\begin{array}{l}\text { no serious } \\
\text { indirectness }\end{array}$ & $\begin{array}{l}\text { no serious } \\
\text { imprecision }\end{array}$ & undetected & 204 & 202 & - & $\begin{array}{l}\text { SMD's g } \\
1.000 \\
\text { lower } \\
\text { ( } 1.481 \\
\text { to } 0.519 \\
\text { lower) }\end{array}$ \\
\hline \multicolumn{11}{|c|}{ Acupuncture vs. control - Outcome: pain (measured with: NPRS, BPI-SF; better indicated by lower values) } \\
\hline $2^{25,26}$ & $\begin{array}{l}\text { randomised } \\
\text { trials }\end{array}$ & $\begin{array}{l}\text { very } \\
\text { serious }^{d}\end{array}$ & $\begin{array}{l}\text { no serious } \\
\text { inconsistency }\end{array}$ & $\begin{array}{l}\text { no serious } \\
\text { indirectness }\end{array}$ & $\begin{array}{l}\text { no serious } \\
\text { imprecision }\end{array}$ & $\begin{array}{l}\text { strongly } \\
\text { suspected }^{\text {e }}\end{array}$ & 24 & 31 & - & $\begin{array}{l}\text { SMD's g } \\
0.817 \\
\text { lower } \\
(1.357 \\
\text { to } 0.278 \\
\text { lower) }\end{array}$ \\
\hline \multicolumn{11}{|c|}{ Compression therapy vs. control - Outcome: pain (measured with: VAS; better indicated by lower values) } \\
\hline $2^{34,37}$ & $\begin{array}{l}\text { randomised } \\
\text { trials }\end{array}$ & $\begin{array}{l}\text { very } \\
\text { serious }^{f}\end{array}$ & $\begin{array}{l}\text { no serious } \\
\text { inconsistency }\end{array}$ & $\begin{array}{l}\text { no serious } \\
\text { indirectness }\end{array}$ & $\begin{array}{l}\text { no serious } \\
\text { imprecision }\end{array}$ & undetected & 33 & 27 & - & $\begin{array}{l}\text { SMD's g } \\
0.292 \\
\text { higher } \\
(0.260 \\
\text { lower to } \\
0.845 \\
\text { higher) }\end{array}$ \\
\hline \multicolumn{11}{|c|}{ NMT vs. sham NMT - Outcome: pain (measured with: VAS; better indicated by lower values) } \\
\hline $1^{32}$ & $\begin{array}{l}\text { randomised } \\
\text { trials }\end{array}$ & serious ${ }^{g}$ & $\begin{array}{l}\text { no serious } \\
\text { inconsistency }\end{array}$ & $\begin{array}{l}\text { no serious } \\
\text { indirectness }\end{array}$ & $\begin{array}{l}\text { no serious } \\
\text { imprecision }\end{array}$ & undetected & 20 & 20 & - & $\begin{array}{l}\text { SMD } \\
2.812 \\
\text { lower } \\
\text { (3.686 } \\
\text { to } 1.938 \\
\text { lower) }\end{array}$ \\
\hline \multicolumn{11}{|c|}{ CDT vs. control - Outcome: pain (measured with: NPRS; better indicated by lower values) } \\
\hline $1^{39}$ & $\begin{array}{l}\text { randomised } \\
\text { trials }\end{array}$ & serious $^{h}$ & $\begin{array}{l}\text { no serious } \\
\text { inconsistency }\end{array}$ & $\begin{array}{l}\text { no serious } \\
\text { indirectness }\end{array}$ & $\begin{array}{l}\text { no serious } \\
\text { imprecision }\end{array}$ & undetected & 20 & 21 & - & $\begin{array}{l}\text { SMD } \\
0.749 \\
\text { lower } \\
\text { (1.382 } \\
\text { to } 0.115 \\
\text { lower) }\end{array}$ \\
\hline
\end{tabular}

Exercise vs. control - Outcome: quality of life (general health) (measured with: SF-36, SF-12; better indicated by higher values)

\begin{tabular}{|c|c|c|c|c|c|c|c|c|c|c|}
\hline $4^{21,33,36,41}$ & $\begin{array}{l}\text { randomised } \\
\text { trials }\end{array}$ & $\begin{array}{l}\text { very } \\
\text { serious }\end{array}$ & very serious ${ }^{\mathrm{j}}$ & $\begin{array}{l}\text { no serious } \\
\text { indirectness }\end{array}$ & $\begin{array}{l}\text { no serious } \\
\text { imprecision }\end{array}$ & undetected & 299 & 152 & - & $\begin{array}{l}\text { SMD's g } \\
0.865 \\
\text { higher } \\
\text { ( } 0.360 \\
\text { to } 1.371 \\
\text { higher) }\end{array}$ \\
\hline
\end{tabular}

Exercise vs. control - Outcome: quality of life (physical health) (measured with: SF-36, SF-12; better indicated by higher values)

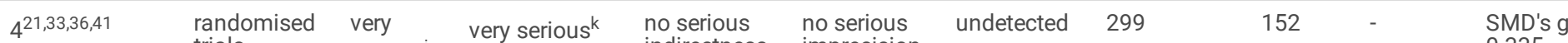
$\begin{array}{llllll}\text { trials } & \text { serious } & \text { very serious } & \text { indirectness imprecision } & & \end{array}$

Exercise vs. control - Outcome: quality of life (mental health) (measured with: SF-36, SF-12; better indicated by higher values)

\begin{tabular}{|c|c|c|c|c|c|c|c|c|c|c|}
\hline $4^{21,33,36,41}$ & $\begin{array}{l}\text { randomised } \\
\text { trials }\end{array}$ & $\begin{array}{l}\text { very } \\
\text { serious }{ }^{i}\end{array}$ & very serious & $\begin{array}{l}\text { no serious } \\
\text { indirectness }\end{array}$ & $\begin{array}{l}\text { no serious } \\
\text { imprecision }\end{array}$ & undetected & 299 & 152 & - & $\begin{array}{l}\text { SMD's g } \\
0.270 \\
\text { higher } \\
(0.030 \\
\text { to } 0.510 \\
\text { higher) }\end{array}$ \\
\hline
\end{tabular}


a Lack of allocation concealment in one trial ${ }^{31}$ (Castro-Martín et al., 2017). Lack of therapist blinding in two trials ${ }^{31,42}$ (Castro-Martín et al., 2017 and Serra-Añó et al., 2018). Lack of assessor blinding in one trial ${ }^{31}$ (Castro-Martín et al., 2017). Analysis not performed on an intention-to-treat basis in one trial ${ }^{31}$ (CastroMartín et al., 2017).

${ }^{b}$ Lack of allocation concealment in three trials ${ }^{35,38,40}$ (Lee et al., 2010, Hwang et al., 2008 and Nyrop et al., 2017). Loss to follow-up in three trials ${ }^{28,29,38}$ (Lee et al., 2010, Hammond et al., 2020 and Ammitzboll et al., 2019). Lack of therapist blinding in five trials ${ }^{28,29,30,35,40}$ (Hammond et al., 2020, Ammitzboll et al., 2019, Cantarero-Vilanueva et al., 2012, Hwang et al., 2008 and Nyrop et al., 2017). Lack of assessor blinding in two trials ${ }^{35,40}$ (Hwang et al., 2008 and Nyrop et al., 2017). Analysis not performed on an intention-to-treat basis in three trials $29,35,38$ (Lee et al., 2010, Hammond et al., 2020 and Hwang et al., 2008 ).

${ }^{c}$ Significant test $(p=0.000)$ of heterogeneity. High $1^{2}(79.776 \%)$.

${ }^{d}$ Lack of allocation concealment in two trials ${ }^{25,26}$ (Quinlan-woodward et al., 2016 and Lu et al., 2020). Loss to follow-up in one trial ${ }^{26}$ (Lu et al., 2020). Lack of therapist and assessor blinding in two trials ${ }^{25,26}$ (Quinlan-woodward et al., 2016 and Lu et al., 2020). Analysis not performed on an intention-to-treat basis in one trial ${ }^{25}$ (Quinlan-woodward et al., 2016).

e Lack of disclosure of conflict of interest (Quinlan-woodward et al., 2016). ${ }^{25}$

${ }^{f}$ Lack of allocation concealment in two trials ${ }^{34,37}$ (Hansdorfer-Korzon et al., 2020 and Johansson et al., 2020). Loss to follow-up in one trial ${ }^{34}$ (HansdorferKorzon et al., 2020). Lack of therapist blinding in two trials ${ }^{34,37}$ (Hansdorfer-Korzon et al., 2020 and Johansson et al., 2020). Lack of assessor blinding in one trial $^{34}$ (Hansdorfer-Korzon et al., 2020). Analysis not performed on an intention-to-treat basis in two trials ${ }^{34,37}$ (Hansdorfer-Korzon et al., 2020 and Johansson et al., 2020).

${ }^{g}$ Lack of therapist and assessor blinding (Conejo et al., 2018). ${ }^{32}$

h Lack of therapist blinding (Ligabue et al., 2019). ${ }^{39}$

' Lack of allocation concealment in one trial ${ }^{41}$ (Paulo et al., 2019). Loss to follow-up in three trials ${ }^{21,33,36}$ (Dong et al., 2019 , Irwin et al., 2008 and GarcíaSoidán et al.,2020). Lack of therapist blinding in four trials ${ }^{21,33,36,41}$ (Paulo et al., 2019, Dong et al., 2019, Irwin et al., 2008 and García-Soidán et al., 2020). Lack of assessor blinding in one trial ${ }^{41}$ (Paulo et al., 2019). Analysis not performed on an intention-to-treat basis in two trials ${ }^{21,33}$ (Dong et al., 2019 and García-Soidán et al., 2020).

i Significant test $(p=0.000)$ of heterogeneity. Very high $\mathrm{l}^{2}(87.758 \%)$.

k Significant test $(p=0.002)$ of heterogeneity. Substantial $I^{2}(72.814 \%)$.

I Insignificant test $(p=0.070)$ of heterogeneity. High $\mathrm{I}^{2}(50.892 \%)$.

Note: CDT $=$ Complex Decongestive Therapy; NMT = Neuromuscular Taping; SMD = Standardized Mean Difference.

\section{Figures}




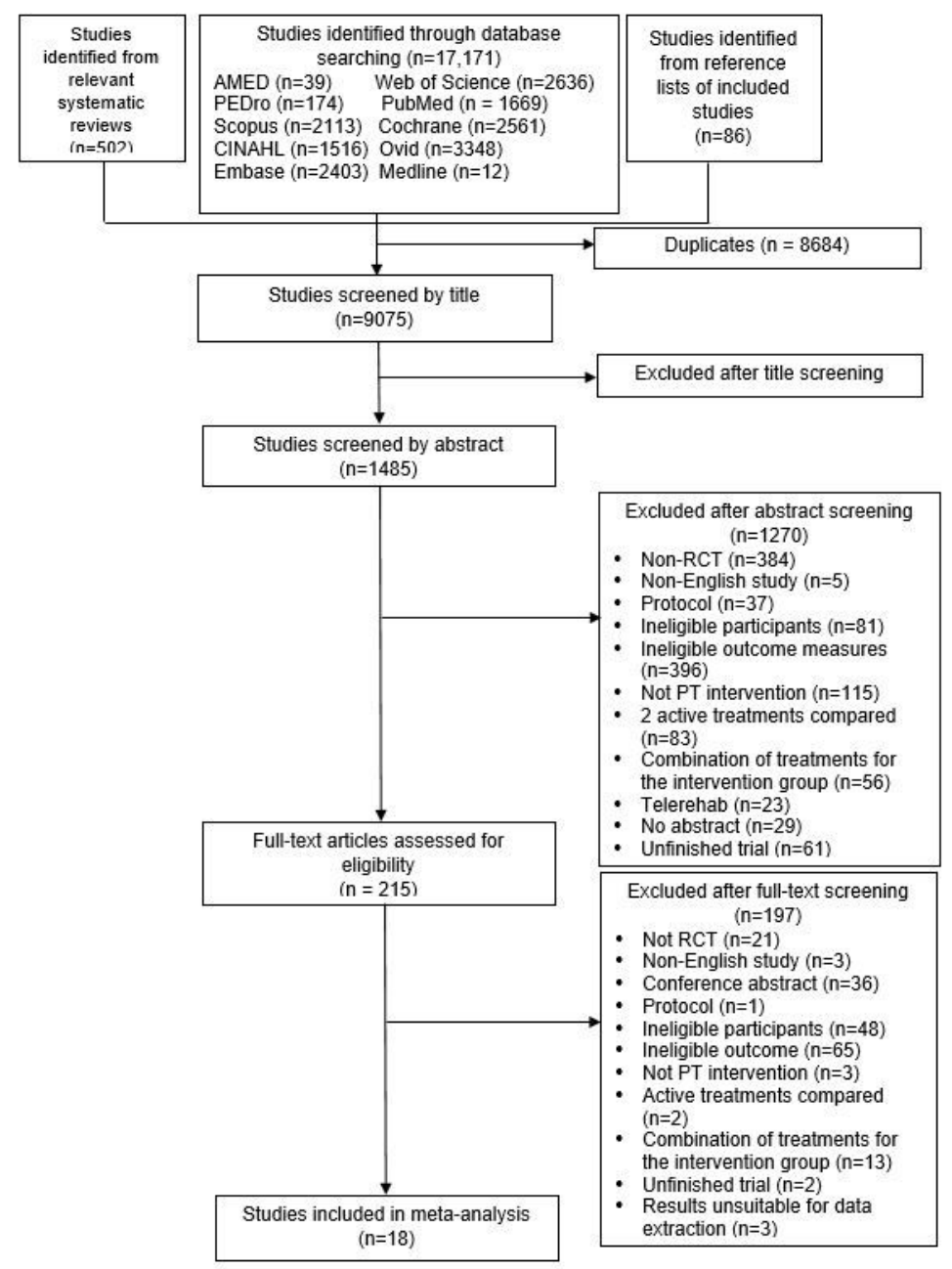

\section{Figure 1}

Flowchart of study selection Note. PT: Physical Therapy 


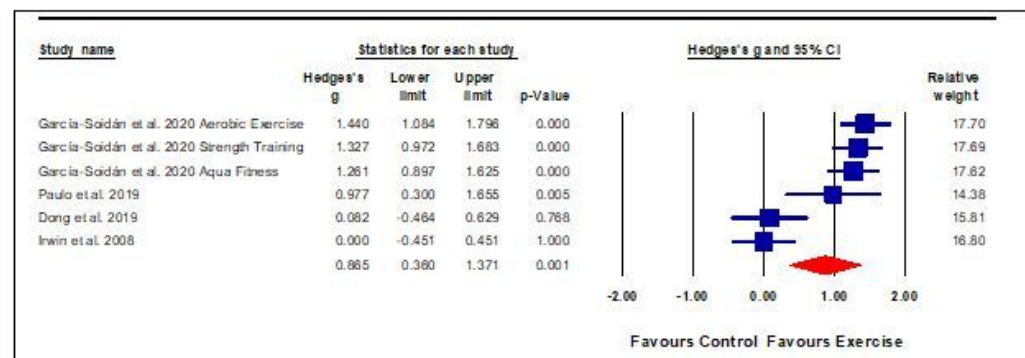

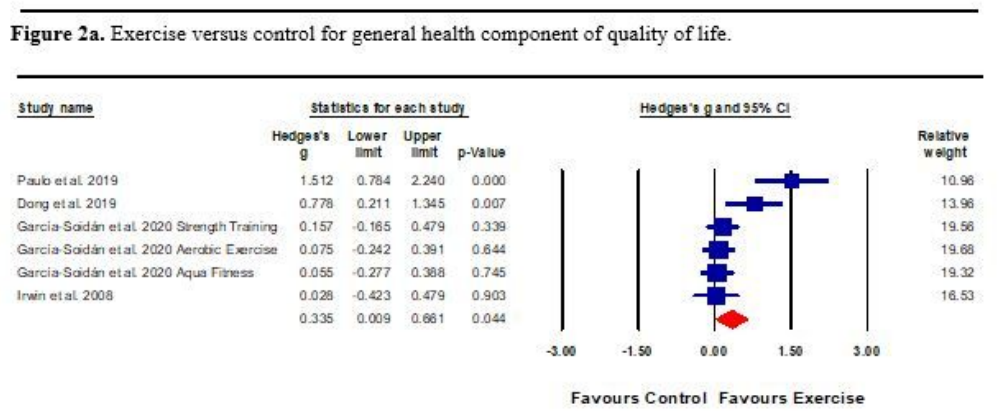

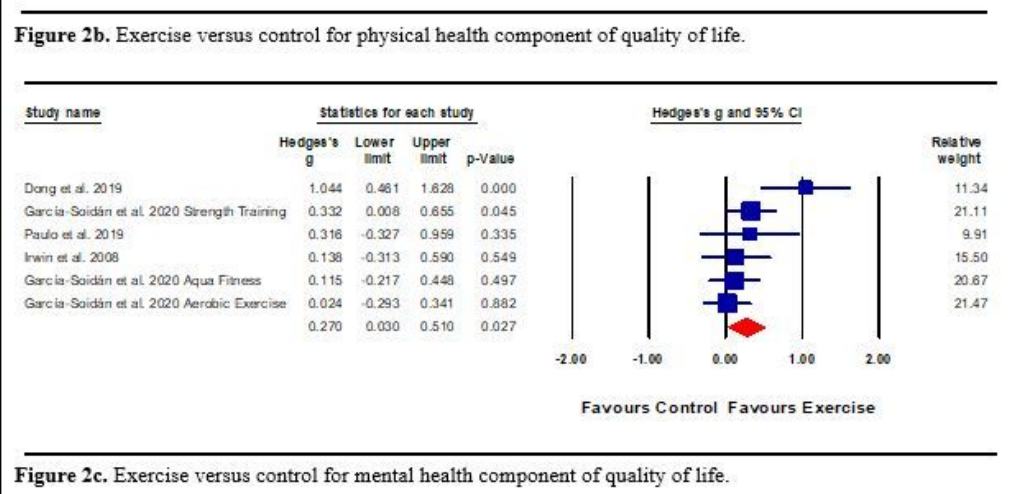

\section{Figure 2}

Effect of interventions on quality of life 


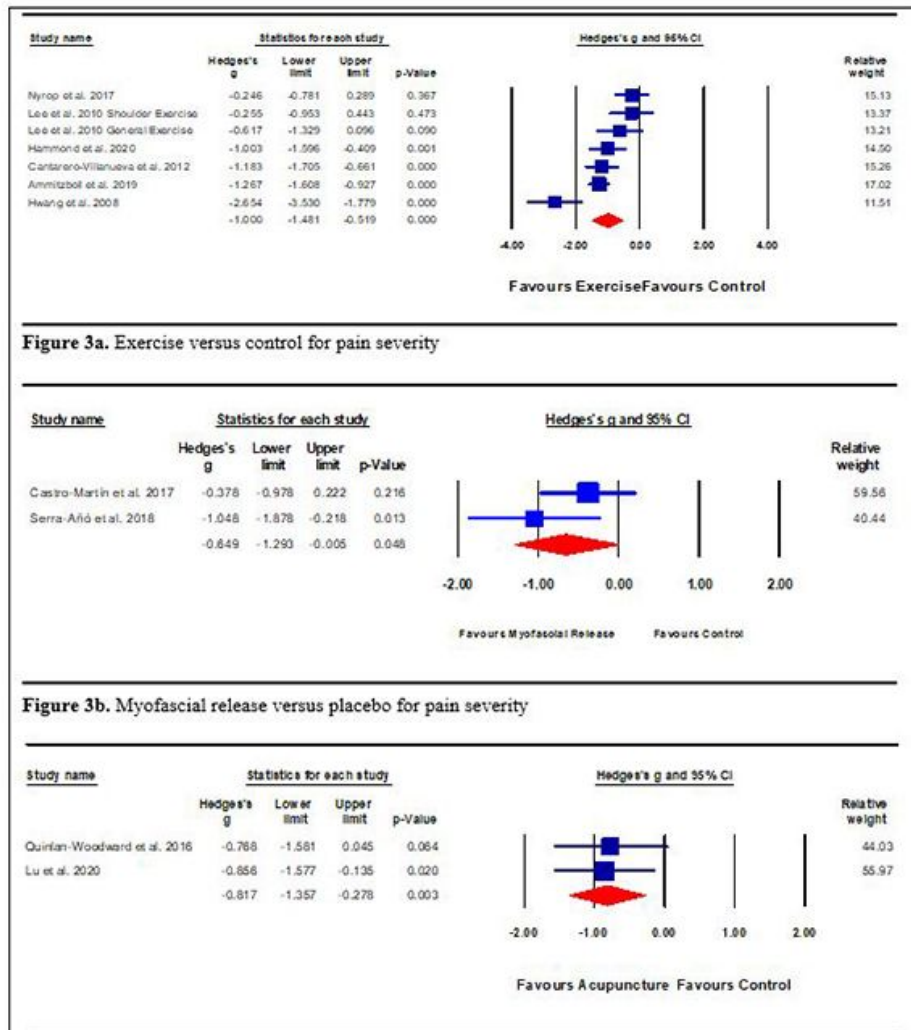

Figure 3c. Acupuncture versus control for pain severity

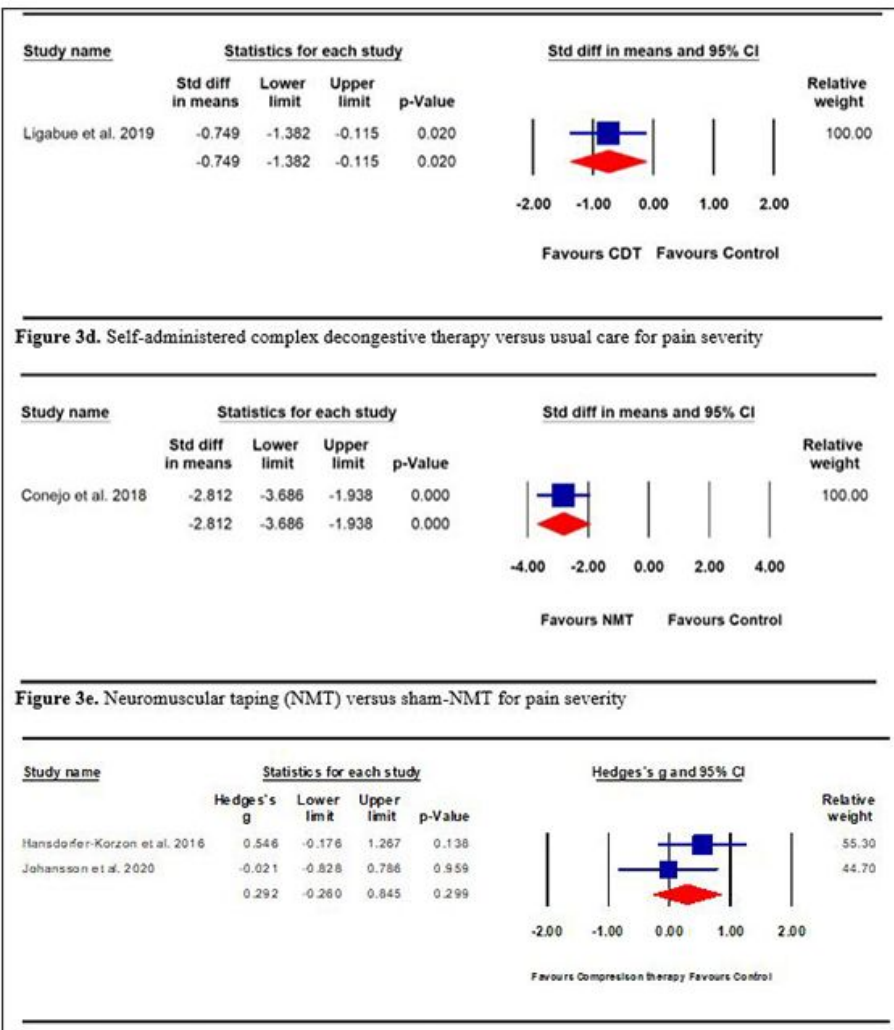

Figure 3f. Compression therapy versus control for pain severity

Figure 3

Effect of interventions on pain severity

\section{Supplementary Files}

This is a list of supplementary files associated with this preprint. Click to download.

- PRISMA2009checklist1.doc

- Supplementaldata.docx 